\title{
Performance of maturity method for estimation of concrete strength based on cubic specimens
}

\author{
Rauan Lukpanov ${ }^{1}$, DShyngys Zharassov ${ }^{1 *}$, (D) Timoth Mkilima², (D)Aliya Aldungarova ${ }^{3}$ \\ ${ }^{1}$ Department of Civil Engineering, L.N. Gumilyov Eurasian National University, Nur-Sultan, Kazakhstan \\ ${ }^{2}$ Pan-African University Institute for Water and Energy Sciences (including Climate Change) c/o Tlemcen University, \\ Tlemcen, Algeria \\ ${ }^{3}$ Department of Architecture and Design, Toraighyrov University, Pavlodar, Kazakhstan \\ *Correspondence: zhshzh95@gmail.com
}

\begin{abstract}
To assess the condition of the structures of buildings and structures, a comprehensive analysis of the factors affecting their performance characteristics - concrete strength, protective layer, and rebar diameter, thermal conductivity and moisture content of concrete, adhesion of protective and facing coatings, frost resistance and water resistance of concrete - is required. However, with all the variety of monitored parameters the control of concrete strength has a special place because when assessing the condition of the structure the determining factor is the compliance of the actual strength of concrete to the design requirements. This paper presents studies on the determination of concrete strength based on modern technology, wireless sensor as well as instrumentation IPS. These methods are particularly effective in the case of non-linear relationships between different system parameters, as in the behavior of concrete parameters. They can also provide rapid measurements by continuously monitoring the internal condition of the reinforced concrete structure. The found graduation dependences and determination coefficients equal to 0.9234 and 0.9702 justify the convergence of the results of the two methods of strength gain control.
\end{abstract}

Keywords: strength gain, sensor, concrete, construction, destructive method, non-destructive method.

\section{Introduction}

Construction is a rapidly growing sector of the economy, undergoing constant changes aimed at improving the quality, operating conditions and reducing the final cost of products. Development of new materials, equipment, and technologies of their production allows to get products with high characteristics of strength, durability, and wear resistance, which gives a reflection not only on the reliability and safety of operation of construction objects but also affects the cost, making construction investments the most attractive from an economic point of view. One of the effective ways to reduce costs is to optimize the construction process. For example, by optimizing formwork removal cycles, it is possible to save time, reduce overhead costs and labor costs [1-2]. Timely detection of the moment of maturity of a reinforced concrete structure and the decision to load it allows for additional profits by reducing the construction time [3]. The method of determining the moment of maturity, which is based on non-destructive methods of controlling the strength of concrete, plays a huge role. Of the many methods for determining the qualitative indicators of nondestructive testing methods are shocking pulse, ultrasonic, temperature-strength [4-7].

The advantages of the shock pulse method are mobility and ease of application. The ultrasonic method works on the principle of sound transmission, experimentally obtained by the dependence of the indicators of the devices on the strength of the material [8]. These devices are used not only to determine the strength but also to determine the timing of setting and hardening, as well as the quality of the reinforcing elements. For instance, this method is well disclosed in [1], which describes the most common methods for compressive strength prediction. The authors confirm this with 
experimental data obtained after testing concrete specimens using non-destructive testing methods. Similar work was performed in [9] where the results show the difference between predicted and actual strength and the average deviation of the test results was $0.18 \%$. Other authors in their paper [10-11], apply non-destructive testing methods to find the strength of samples taken from the existing concrete structure and then the same samples are crushed on a press in the laboratory. In any case, all nondirect methods of strength control are indirect and, therefore, may have measurement errors. Today, one of the promising methods of nondestructive testing, which is still little used in our construction market, is the temperature-strength method. This method allows you to determine the quality of the material depending on the temperature changes in the process of hydration of the concrete mixture. Sensor sensors register the quality indicators with the smallest error, and also allow controlling the hydration process of concrete from the beginning of hardening up to 28 days and even during the entire life cycle of the concrete structure, if necessary [12-13]. In this regard, the relevance of this article lies in the use of the above-mentioned sensors of domestic production, and a series of field and laboratory tests with widely used concrete on construction sites in the city gives an understanding of its temperature-strength behavior.

\section{Methods and materials}

The study included several stages:

1. Preparation of large samples (LS) of standard composition, size more than 50x50x50, with the installation of temperature sensors (Figure 1a). Carrying out operational control of the strength of large samples (road slab) by ultrasound. Determination of the temperature strength by the method [14].

2. Preparation of small samples (SS) of the same composition, cubic shape of size $15 \times 15 \times 15$ with the installation of temperature sensors (Figure 1b).

Measurements of SS and LS: continuous temperature measurement; daily strength measurement by non-destructive method (ultrasonic method); control measurement of the compressive strength of selected cylinders on 3, 7, 14, 21, and 28 days (3 samples each).

3. Determination of the functional dependencies of SS and LS to adjust the dependency.

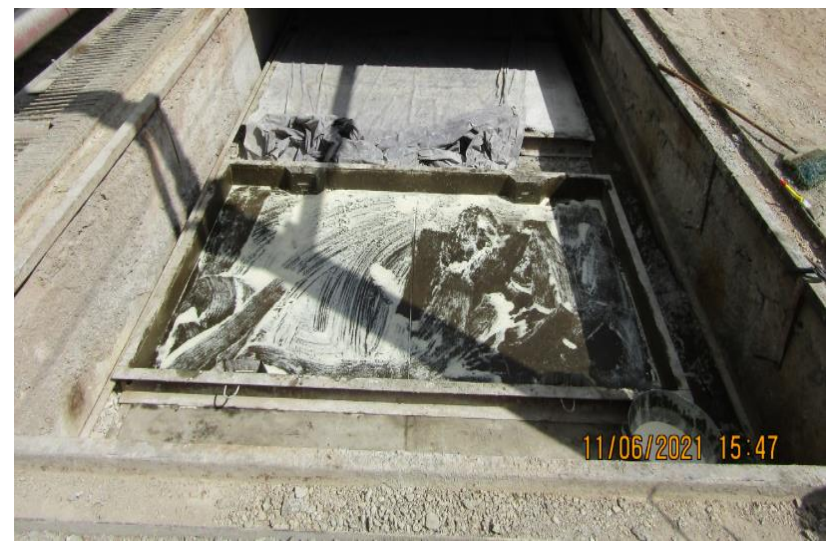

a) LS

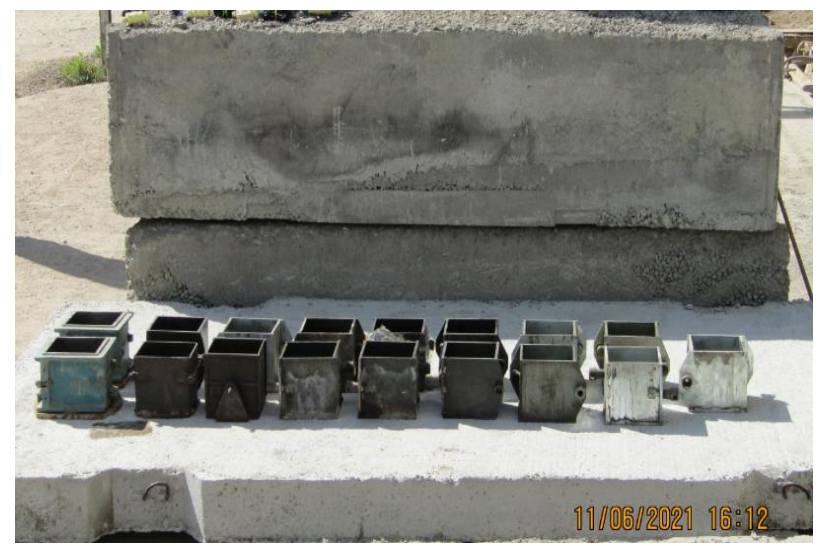

b) SS

Figure 1 - Sample preparation

The strength tests of the samples by the non-destructive testing method are performed by the shock-pulse device IPS MG-4 [15]. This method (Figure 2) belongs to the express method, however, it is an indirect estimation of strength characteristics of structures, it requires the establishment of calibration dependence with the destructive method [16], performed on the test press. For a general visualization of the trend of concrete strength gain of a production batch of a particular factory composition, Figure 3 shows the concrete strength gain plots for all 17 samples. The trend of strength gain, in general, is proportional, the width of the range bounded by the edge curves is relatively the 
same, indicating a close relationship between the individual measurement values and the minimal assumption of random variables.

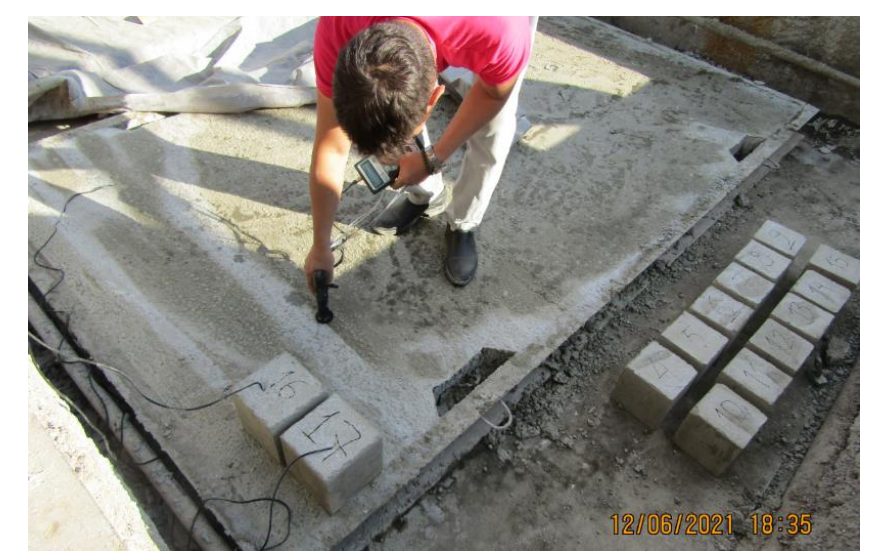

Figure 2 - Operational control of the strength of large samples (road slab) by ultrasound method

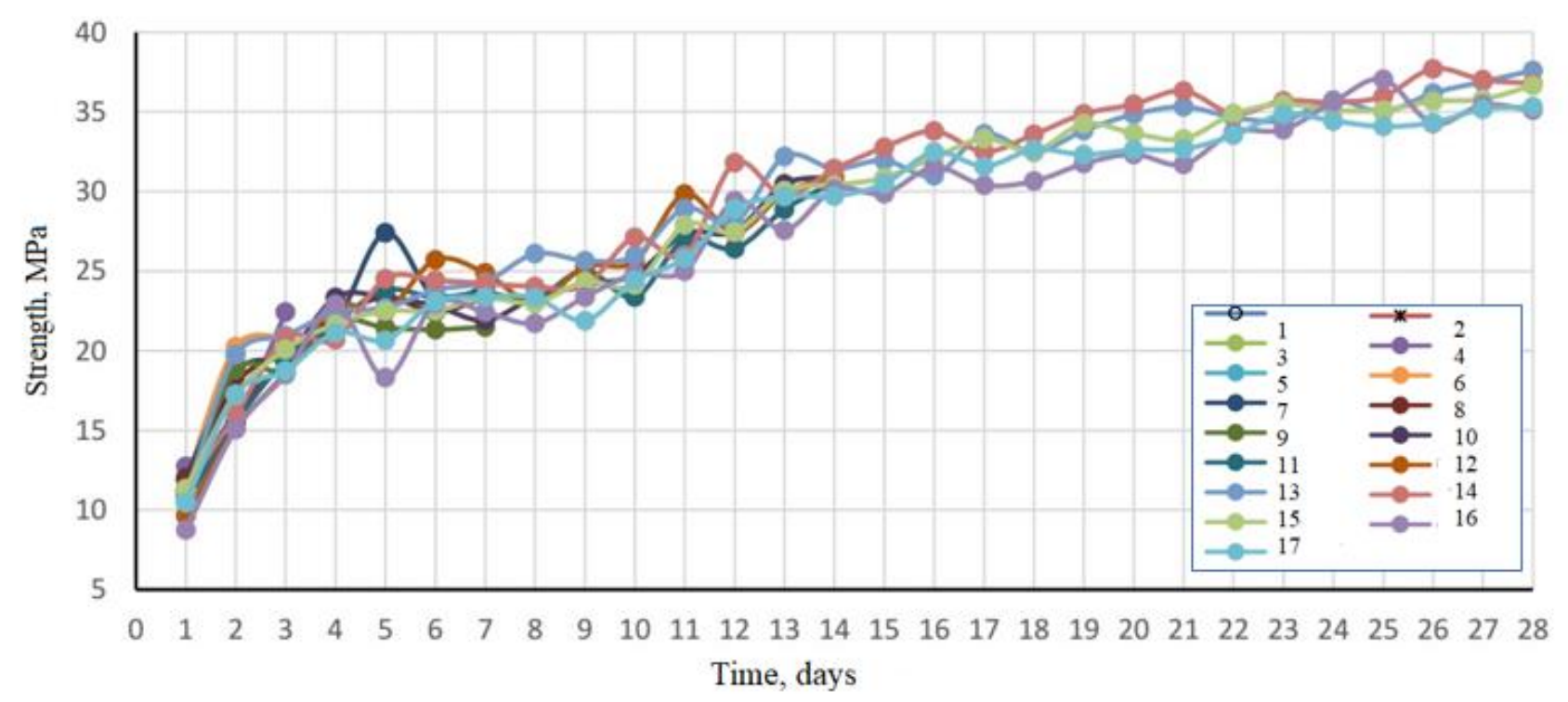

Figure 3 - Graphs of strength for 17 specimens

A self-developed measuring device (Figure 4) consisting of the following components was used to measure the temperature mode of concrete hardening:

- 4 temperature sensors type DS18B20;

- 2 lithium-ion batteries, rated $3.7 \mathrm{~V}$ and $3000 \mathrm{mAh}$ capacity;

- atmega328p microcontroller (this microprocessor possessing 8-bit AVR microcontroller with $32 \mathrm{~KB}$ programmable Flash memory is relatively cheap compared to other energy-efficient microcontrollers, as well as has a compact TQFP32 package).

- 8GB memory card for storing records for 28 days;

- time module of DS3231 type, so that the device periodically wakes up and polls the sensors connected to it.

This device is capable of performing the following functions: to measure the temperature with an accuracy of not more than $+/-1^{\circ} \mathrm{C}$; has guaranteed performance of 1 month, in operating mode, the microcontroller on an electronic board interrogates the temperature sensor connected through a cable inside the concrete with a given frequency and records the data on the SD card.

Registration of data on temperature changes, processing, and analysis of research results were carried out according to the methodology regulated by [14]. Before the measurements, the 
temperature sensors were calibrated to a maximum error of $\pm 1^{\circ} \mathrm{C}$. Temperature measurements were taken at intervals of every 30 minutes.

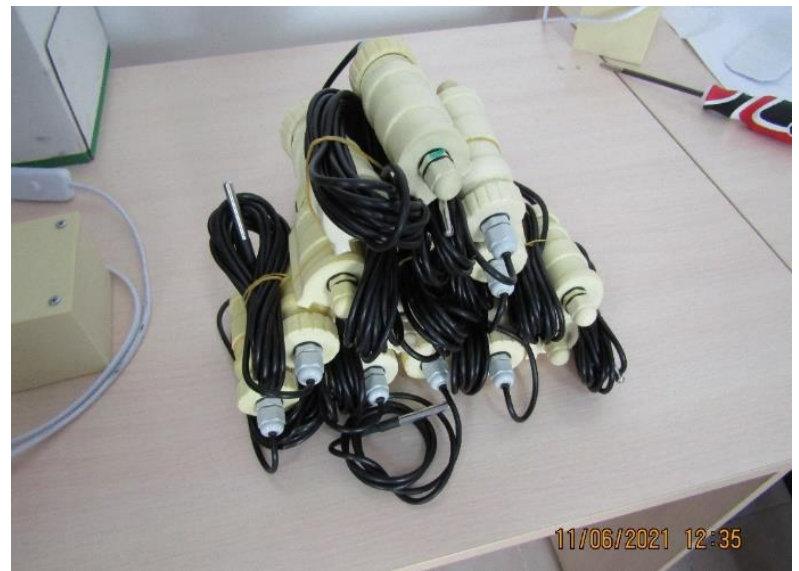

a) Sensor

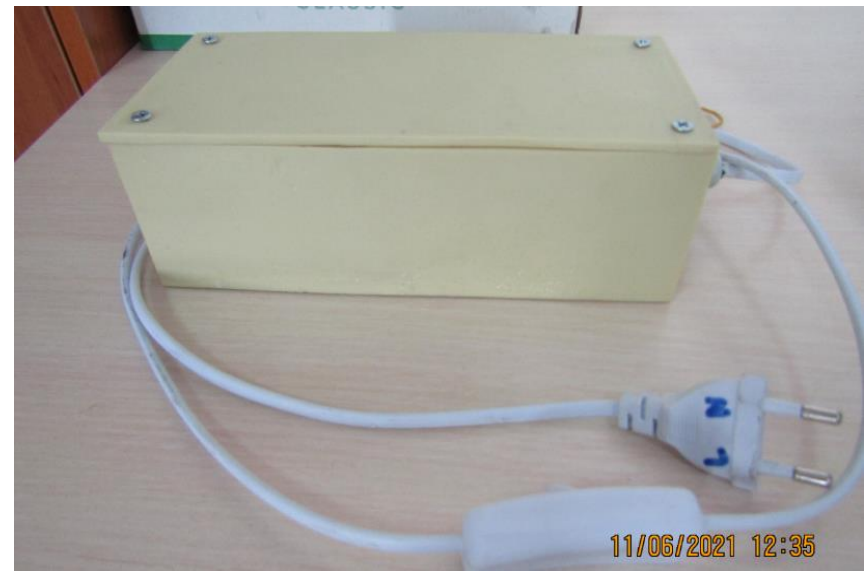

b) Data collection device

Figure 4 - Concrete strength control sensor

According to [14] the concrete maturity function is used to calculate the temperature-time factor:

$$
M(t)=\sum\left(T_{a}-T_{0}\right) \Delta t
$$

$\mathrm{M}(\mathrm{t})$ - the temperature-time factor at age $\mathrm{t}$, degree-days, or degree-hours;

$\Delta t$ - time interval, days or hours;

$T_{a}$ - average concrete temperature during the time interval, $\Delta t,{ }^{\circ} \mathrm{C}$;

$T_{0}$ - datum temperature, ${ }^{\circ} \mathrm{C}$.

The process of drilling core samples of reinforced concrete road slabs to control the cylindrical compressive strength is shown in Figure 5.

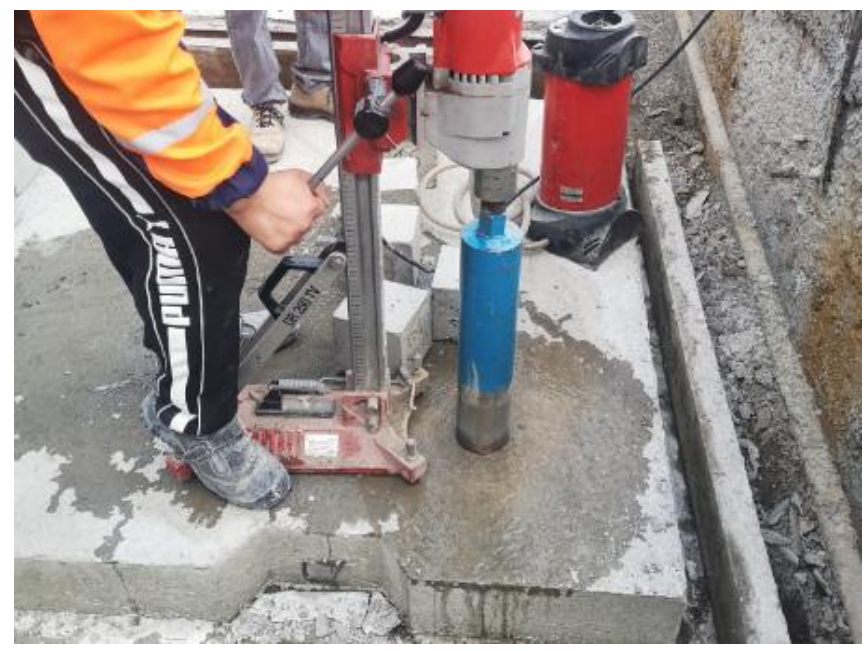

Figure 5 - Process of drilling core samples

\section{Results and Discussion}

The result of the ASTM formula based on Eq. (1), is a strength graph of the cylindrical concrete specimens compression results, i.e. Figure 6 shows graphs of strength gain vs. time of concrete curing (age of concrete). 


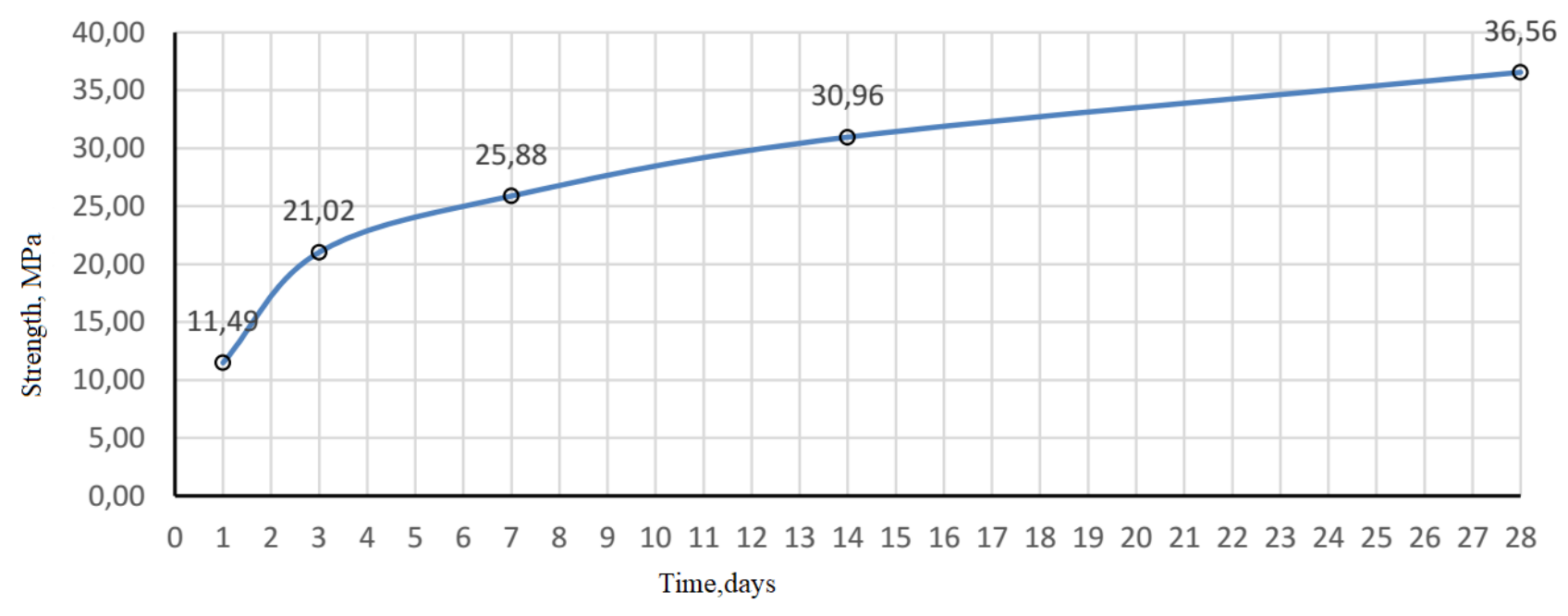

Figure 6 - Concrete strength gain graph

In general, the tendency of strength gain is classical, relatively uniform strength gain over time is observed, the change of partial strength values is smooth, without sharp jumps.

According to the definition in [15], the found graduation dependence in Figure 7 is the relationship between the indirect strength characteristic and the compressive strength of the concrete specimen. As can be seen in the graph, the formula of analytical dependence is expressed as a linear function and its coefficient of determination with finding the trend line. The coefficient of determination equal to 0.9234 close to 1 says about reliability of the found graduation dependence.

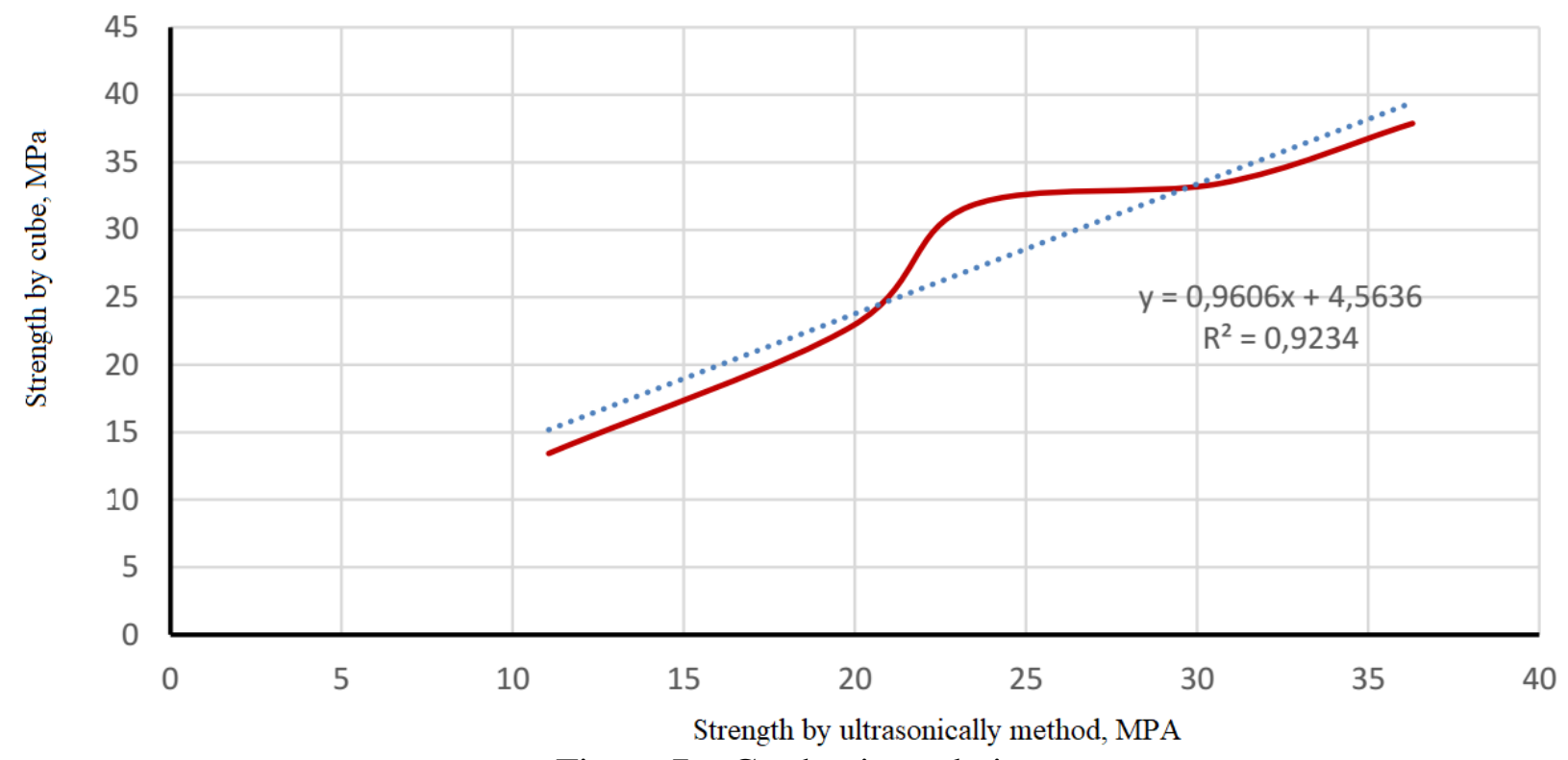

Figure 7 - Graduation relation

Then a graduation relationship between the temperature-strength control methods was found in a similar way of calculation. The plotted graph in Figure 8 is comparable to the standard graph of concrete strength gain, which is based on the normative-safe time of strength gain, where ideally at $30^{\circ} \mathrm{C}$ the optimal normative strength gain in 11 days should exceed the design strength and reach up to $97 \%$ of the projected strength. In this case, the logarithmic function describes the resulting trend line better than anything else, and the coefficient of determination is close to 1 . 


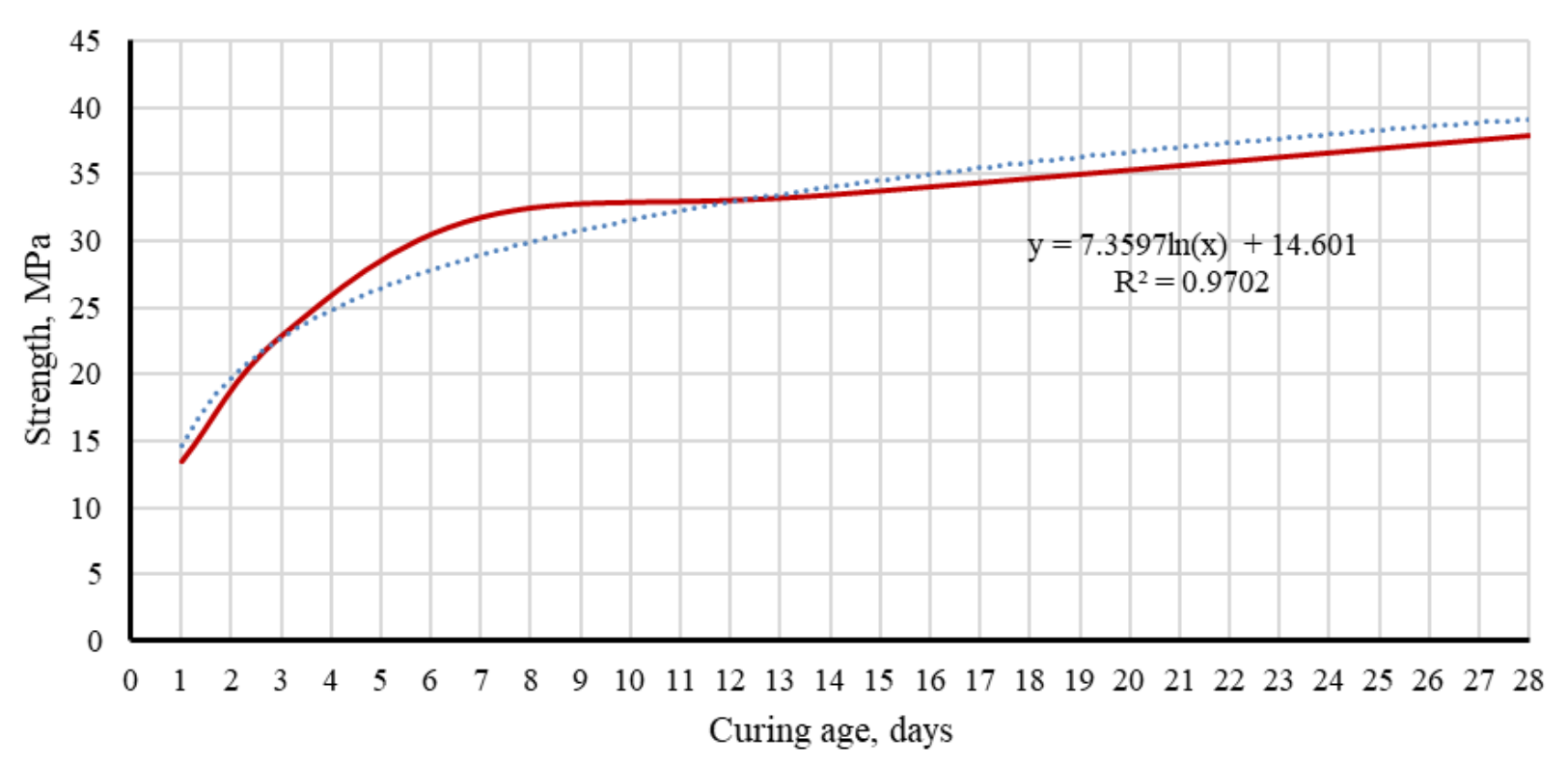

Figure 8 - Strength gain chart by maturity method

Thus, the results obtained in the course of the study substantiate the relevance of the use of temperature-strength control of concrete strength gain.

\section{Conclusions}

The strength of concrete is an important parameter by which to ensure the durability of a building or structure. The results showed sufficient convergence of the results, which confirms their reliability. These methods of determining the strength of concrete are used on construction sites around the world. The study showed that the temperature factor is fundamental in the formation of the required properties of the concrete structure. Also, a special feature was using of cubic specimens for research.

Whereas according to the standard, cylindrical samples of at least 15 pieces are used. Thus, the study can be identified certain techniques and objectives, the methods used in them (methods of temperature-strength control of concrete), which, and led to the effectiveness of the results.

\section{Acknowledgments}

This research was funded by the Science Committee of the Ministry of Education and Science of the Republic of Kazakhstan (Grant № AP08052033).

\section{References}

1. Concrete compressive strength prediction using non-destructive tests through response surface methodology / A. Poorarbabi, M. Ghasemi, M. Azhdary Moghaddam // Ain Shams Engineering Journal. — 2020. — Vol. 11, No. 4. — P. 939-949. https://doi.org/10.1016/j.asej.2020.02.009

2. Determination of concrete quality with destructive and non-destructive methods / H. Kibar, T. Ozturk // Computers and Concrete. — 2015. - T. 15, № 3. - P. 473-484. https://doi.org/10/gm55ms

3. Strength Prediction by Using Maturity for Portland Cement Concrete Pavement Construction at Airfields / R.O. Rasmussen, J.K. Cable, D.J. Turner, G.F. Voigt // Transportation Research Record: Journal of the Transportation Research Board. - 2004. — Vol. 1893, No. 1. — P. 18-25. https://doi.org/10.3141/1893-03

4. Closure to "Load Transfer Curve Analyses of Drilled Shafts Using Crosshole Sonic Logging Test" by Won-Taek Hong, Seung Yong Shin, Min-Chul Park, Jong-Sub Lee, and Myung Jun Song / W.-T. Hong, S.Y. Shin, M.-C. Park, J.-S. Lee, M.J. Song // Journal of Geotechnical and Geoenvironmental Engineering. — 2020. — T. 146 , № 7. — C. 07020009. https://doi.org/10.1061/(ASCE)GT.1943-5606.0002285 
5. A review on sensors and systems in structural health monitoring: current issues and challenges / M.A. Hannan, K. Hassan, K.P. Jern // Smart Structures and Systems. — 2018. — Vol. 22, No. 5. — P. 509-525. https://doi.org/10.12989/SSS.2018.22.5.509

6. Non-destructive concrete strength evaluation using smart piezoelectric transducer-a comparative study / Y.Y. Lim, K.Z. Kwong, W.Y.H. Liew, C.K. Soh // Smart Materials and Structures. — 2016. — Vol. 25, No. 8. — P. 085021. https://doi.org/10.1088/0964-1726/25/8/085021

7. Modeling a set of concrete strength in the program ELCUT at warming of monolithic structures by wire / M.O. Dudin, N.I. Vatin, Yu.G. Barabanshchikov // Magazine of Civil Engineering. — 2015. — Vol. 54, No. 02. — P. 33-45. https://doi.org/10.5862/MCE.54.4

8. Nondestructive Evaluation of Damage in GFRP Bars Using Ultrasonic Guided Waves / P. Wiciak, M.A. Polak, G. Cascante // Journal of Composites for Construction. - 2021. — Vol. 25, No. 6. — P. 04021055. https://doi.org/10.1061/(ASCE)CC.1943-5614.0001166

9. The Behavior of Non-Destructive Test for Different Grade of Concrete / M. Abdul Rahim, S. Shahidan, L.C. Onn, Poh Cheong (Malaysia) Sdn Bhd, Lot 1250/1251 Jalan Seelong, 81400 Senai, Johor, MALAYSIA, N.A.A. Saiful Bahari, N. Abd Rahman, A. Ayob // International Journal of Integrated Engineering. — 2020. — Vol. 12, No. 9. https://doi.org/10/gnq334

10. The Relationship Between Concrete Strengths Obtained by Destructive and Non-destructive Methods / Ş. Karahan, A. Büyüksaraç, E. Işı // Iranian Journal of Science and Technology, Transactions of Civil Engineering. - 2020. — Vol. 44, No. 1. — P. 91-105. https://doi.org/10/gnq2sz

11. Compressive strength and elasticity module of concrete using non-destructive techniques (NDT) / M.V. de Camargo, V.J. Ferrari // Matéria (Rio de Janeiro). — 2021. — Vol. 26, No. 3. — P. e13047. $\underline{\text { https://doi.org/10/gnq34d }}$

12. The early-age prediction of concrete strength using maturity models: a review / K. Nandhini, J. Karthikeyan // Journal of Building Pathology and Rehabilitation. - 2021. - Vol. 6, No. 1. — P. 7. https://doi.org/10.1007/s41024-020-00102-1

13. Comparison of calculating methods and applications of different concrete maturity / D. Geng, N. Dai, X. Jin, E. Miao // Journal of Physics: Conference Series. — 2021. — Vol. 2011, No. 1. — P. 012022. https://doi.org/10.1088/1742-6596/2011/1/012022

14. Standard Practice for Estimating Concrete Strength by the Maturity Method / ASTM C1074-17 — P. 10.

15. Concretes. Determination of strength by mechanical methods of nondestructive testing / GOST 22690 - P. 24.

16. Concretes. Methods for strength determination using reference specimens / GOST 10180 — P. 36 .

\section{Information about authors:}

Rauan Lukpanov - PhD, ENU-Lab, L.N. Gumilyov Eurasian National University, Nur-Sultan, Kazakhstan, rauan_82@mail.ru

Shyngys Zharassov - PhD Student, Department of Structural Engineering, L.N. Gumilyov Eurasian National University, Nur-Sultan, Kazakhstan, zhshzh95@gmail.com

Timoth Mkilima - Pan-African University Institute for Water and Energy Sciences (including Climate Change) c/o Tlemcen University, Tlemcen, Algeria, tmkilima@ gmail.com Aliya Aldungarova - PhD, Associate Professor, Department of Architecture and Design, Toraighyrov University, Pavlodar, Kazakhstan, liya_1479@mail.ru 